\title{
Medical Students' Knowledge Level about X-Ray as a Diagnostic Support Tool at Universitas Kristen Indonesia, Jakarta Batch 2016
}

\author{
Richard Yan Marvellini \\ Medical Faculty, Universitas Kristen Indonesia, Jakarta, Indonesia
}

DOI: https://doi.org/10.52403/ijhsr.20220242

\begin{abstract}
The study is aimed at investigating the medical students' knowledge level about x-ray as a diagnostic support tool. It was done at Universitas Kristen Indonesia. The type of research is in the form of quantitative descriptive, which aims to systematically, factually, and accurately regarding the level of knowledge. Research data collection was carried out using a cross-sectional research design. The population in this study were all medical students of the Universitas Kristen Indonesia, batch 2016. The respondents were medical students, batch 2016 semester 1, who had just graduated from high school and entered the university level to see respondents' level of knowledge about X-rays for about 100 respondents. The instrument of this study was a set of questionnaires which had been tested to 30 UKI students from the 1st semester of pediatric medicine faculty. Researchers carried out data processing through editing, coding, processing, and cleaning stages. The researcher used univariate and bivariate analysis to analyze the research results. The result of the research is that most of the respondents have a high level of knowledge of X-Ray, and the source most often used by students to find information about X-Ray is electronic media. Based on the bivariate analysis results, the p-value obtained is 0.000 , which means that there is a significant relationship between the respondent's school origin and the level of knowledge of X-rays.
\end{abstract}

Keywords: X-Ray, Diagnostic Support Tool, Students' Knowledge

\section{INTRODUCTION}

Along with the times, humans or medical experts use technology to assist treatment and imaging. One of the technologies developed among medical experts to diagnose patients is X-Rays. Wilhelm Conrad Roentgen is a physicist at the University of Wurzburg, Germany, who discovered X-rays in 1895 while conducting experiments with cathode rays. Roentgen's discovery is a revolution in the world of medicine because it turns out that with the results of this discovery, parts of the human body can be examined, which previously could not be achieved by conventional means [1].

$\mathrm{X}$-rays, generally called X-rays, are helpful for the therapy and diagnosis of a disease. X-rays can penetrate the human body but are absorbed by denser parts such as bone. Soft X-rays take still images known as radiographs [2]. Medical experts use these X-ray images to detect bone defects, detect broken bones, and investigate the condition of internal organs' condition, while hard x-rays can be used to destroy cancer cells. This method is known as radiotherapy $[3 ; 4]$.

The use of $\mathrm{x}$-rays for diagnosis is very beneficial because the examiner can know the condition in the patient's body without performing surgery on the patient. However, in addition to providing beneficial properties, $\mathrm{x}$-rays also provide destructive properties, namely the rays emitted from general $\mathrm{x}$-rays. It has ionizing properties to 
tissue in its path so that if the x-rays hit humans in excess, it can cause harmful effects. 3. Excessive x-rays will affect all organs and systems in the body. However, because not all organs or systems have the same sensitivity to $\mathrm{x}$-rays, the response patterns or disease syndromes in people who experience excessive radiation depend on the amount of radiation dose [5].

Because of the effects that are very dangerous for humans who are exposed to excessive exposure to these $\mathrm{x}$-rays, to minimize the effects, it is necessary to know the self-protection system on $\mathrm{x}$-rays to ensure safety for patients, operators and the general public [6]. The increasingly widespread use of X-rays in the medical world encourages the author to find out more about how high the level of knowledge of medical students in the new academic year at UKI is regarding the use of $\mathrm{X}$-Ray as a diagnostic support tool in the medical world. The formulation of the research problem is "what is the level of knowledge of UKI medical students class 1 of 2016 for X-rays as one of the supporting examination tools to establish a diagnosis in medicine?". The purpose of the study is to determine the level of knowledge of UKI medical students batch 2016 semester one about the use of X-rays (X-Ray) as one of the supporting examination tools to establish a diagnosis.

\section{LITERATURE REVIEW}

$\mathrm{X}$-rays were first discovered by the German physicist Wilhelm C. Roentgen on November 8, 1895. At that time, Roentgen was working using a Crookes tube in his laboratory at the University of Wurzburg. he saw the emergence of fluorescent light emanating from barium platinocyanide crystals in an electrified Crookes-Hittorf tube. He soon realized that this phenomenon was a discovery, so he persistently continued his investigations. Not long after, a ray was discovered, which he called a new ray or X-ray. People later named the ray the Roentgen ray in honour of Wilhelm Conrad Roentgen [1].
X-rays are electromagnetic waves emitted similar to electricity, radio, infrared heat, light, gamma rays, cosmic rays and ultraviolet light but with very short wavelengths. X-rays are heterogeneous. Their wavelengths vary and are invisible. The difference between light and other electromagnetic rays lies in the wavelength of X-rays is very short, which is only $1 / 10,000$ of the visible wavelength of light. It is what causes X-rays to penetrate objects. The wavelength of electromagnetic light is expressed in Angstroms [7].

\section{$1 \mathrm{~A}=1 / 100.000 .000 \mathrm{~cm}=10-8 \mathrm{~cm}$}

The waves used in medicine are between $0.50 \mathrm{~A}-0.125 \mathrm{~A} .7$

$\mathrm{X}$-rays have several physical properties, namely: penetrating power, scattering, absorption, photographic effects, fluorescence, ionization and biologic effects [8]. Penetrating light examination is a radiological examination where radiologists can directly see and study moving body organs. X-rays pass through the patient's body and hit the phosphorescent crystals, flour (fluorescent), on the screen so that these parts can be seen. Because the X-rays received by the examiner and the patient are pretty high, penetrating light examination of the lungs is no longer allowed, instead of using an image intensifier with a TV camera without darkening the examiner's room.

Radiography is the making of recording films (radiographs) of internal body tissues by passing X-rays or gamma rays to the body to print images on a particular sensitive film [9]. The type of $\mathrm{x}$ ray examination is through essential $\mathrm{X}$-ray examination, $\mathrm{X}$-ray examination with contrast material, and special X-ray examination.

X-ray penetrating power varies according to the object through which it passes. Objects that are easily penetrated by $X$-rays will give a black image (radiolucency). Objects that are difficult for $\mathrm{X}$-rays to penetrate will give a white image (radiopaque). Intermediate shadows are not 
too black or moderately radiolucent and not too white or radio-opaque (moderately radio-opaque) [10]. There is a whitish shadow (intermediate). Based on the ease with which X-rays penetrate, the body parts are divided into a) Radiolucent (black): gas and air; b) Medium radiolucent: fatty tissue; c) Whitish: connective tissue, muscle, blood, cartilage, epithelium, cough, cholesterol, uric acid stones; d) moderately radiopaque: bone and calcium salts); and e) Radiopaque (white): heavy metals [6].

The sequence of the X-ray process is as follows: a) The cathode (filament) is heated (more than $20000 \mathrm{C}$ ) until it turns on, flowing electricity from the transformer; $b$ ) Due to heat, electrons from the cathode (filament) are released; c) When connected to a high-voltage transformer, the electrons will be accelerated towards the anode and focused on the focusing cup; d) Filaments are made negative relative to the target (target) by selecting high potential; e) Electron clouds suddenly stopped at the target (target) so that heat (> 99\%) and Xrays $(1 \%)$; $f$ ) Tin shield will prevent $X$-rays from coming out of the tube, so X-rays that are formed can only come out through the window; and g) High heat on the target (target) due to the impact of electrons is dissipated by the cooling radiator. The number of X-rays released per unit of time can be seen on a milliampere (MA) measuring device, while the shooting time is controlled by a timer $[6 ; 11]$.

$\mathrm{X}$-rays, generally called $\mathrm{x}$-rays, are useful for the therapy and diagnosis of a disease. The use of x-rays for diagnosis is very beneficial because it can know the condition in the body without surgery or division of the patient. In addition, X-ray has several advantages, including a) Diagnosing something in a relatively short term; b) Non-invasive (without surgery or surgery); c) Has a relatively small effect on both the operator and the patient if performing safety procedures correctly; d) Can diagnose the whole human body; e) To monitor the development of a type of diseases, such as osteoporosis, arthritis, blockage of blood vessels, bone cancer, breast tumours, digestive disorders, enlargement of the heart, various types of infections, and tooth decay; f) As radiotherapy to kill tumour and cancer cells; and g) Sterilizing medical equipment [8; 12]. Radiation can be divided into two: ionizing radiation, which consists of electromagnetic radiation and particles. The next radiation is non-ionizing radiation [13].

The interaction of $\mathrm{x}$-rays with biological cells has direct and indirect effects. Direct effects arise due to the ionization or excitation of cell parts exposed to direct radiation exposure, while indirect effects arise due to the interaction of materials produced by direct effects with the components that make up the cells. Because cells are composed of carbohydrates, fats, proteins, and about $70 \%$ of cells are composed of water, the interaction of radiation with the main components of this arrangement causes the formation of chemicals from cells. The effects of radiation based on the type of dose are a) Radiation in a short time (acute) which generally occurs by chance (accident). Acute irradiation involving high doses of irradiation can cause immediate biological effects, i.e. effects that appear less than one year from the occurrence of irradiation.

Nevertheless, acute irradiation can cause delayed biological effects if the radiation dose is low, and b) Broadcasting by low but continuous (chronic) radiation doses. This type of irradiation usually does not immediately show its effect, so it is called a delayed effect. This effect can appear after several years or even decades since the occurrence of irradiation.

Excessive radiation exposure that is acute to the whole body will affect all organs and systems in the body. However, because not all organs or systems have the same sensitivity to radiation, the response patterns or disease syndromes in people who experience excessive radiation depend on the number of doses [14].

The amount of radiation that is exposed to an object (or person or tissue) 
can be measured in energy (joules) stored per unit mass (kilogram) of whatever is exposed to radiation. The specific SI unit for radiation is the grey (Gy), defined as one joule per kilogram. Various biological tissues have different responses to different types of radiation, and to measure it, the biological weight factor is used. The SI unit of biologically effective dose is the sievert $(\mathrm{Sv})$. This effective dose is also measured in joules per kilogram but is used to calculate the biologic response of a particular tissue to irradiation [15].

Radiation protection is a branch of science related to environmental health techniques, namely, the protection that needs to be given to a person or group of people against the possibility of obtaining negative consequences from ionizing radiation. In contrast, the activities required to use ionizing radiation sources are still carried out. Radiation protection is an action taken to reduce the damaging effects of radiation due to radiation exposure [16]. Because of the effects that are very dangerous for humans exposed to radiation exposure, to eliminate the effects caused, it is necessary to have a radiation protection system.

There is a new philosophy in radiation protection that refers to ICRP No. 60 of 1990, namely to achieve the goal of radiation protection, namely the creation of safety and health for workers, the community and the environment. This philosophy consists of 3 principles of radiation protection, namely justification, optimization, and limitation [17]. According to the Regulation of the Head of the Nuclear Energy Supervisory Agency, No. 8 of 2011 concerning Radiation Safety in the Use of Diagnostic and Interventional Radiology XRay Aircraft, X-ray radiation safety has several essential elements that are applied as the basis for the formation of a Radiation Safety Management System (SMKR) [18].

$\mathrm{X}$-Ray Dosage on Radiation Officers Radiation personnel must be monitored at all times while at work. The reason for monitoring is to ensure that the work performed by the staff in their daily routine is safe and does not lead to the reception of high doses. If monitoring is not carried out, unsafe work will not be monitored to cause overexposure to officers.

Monitoring of personnel should be the responsibility of national authorities. They are supposed to supply pre-packed thermoluminescent dosimeters, which are returned for automatic readings in monthly cycles. The dosimeter should be worn on the body and under lead-lined clothing that acts as a shield. All radiation personnel must wear their dosimeter at all times during working hours [19]. If the monthly limit is exceeded, the officer in charge of protection must be notified and make a report.

In addition to radiation protection that has been applied, at the time of radiation exposure to patients, radiation protection also needs to be carried out by external is radiation produced by devices designed to produce radiation: minimizing irradiation time, maximizing distance from radiation sources and protecting radiation sources so that the radiation source is only centred on the object.

The dose of skin exposed during $\mathrm{X}$ ray examination has decreased over the years with newer technical equipment that uses more sensitive detectors and better shielding-however, the ability to expose large radiation doses quickly and easily increases. Generally, the dose administered is lower than the threshold for a deterministic effect, but interventional radiology and similar lengthy procedures can cause hair loss (>3000 mSv).

Personal Protective Equipment (PPE) is a piece of equipment that must be used when working according to work hazards and risks to maintain the workers' safety and those around them [20]. Personal protective equipment commonly used by radiation workers are body protection aprons, gonadal radiation shields, protective gloves, radiation shields, masks, and gloves.

Knowledge is knowledge or everything that is known about things. Knowledge results from knowing after 
someone senses a particular object. Knowledge is an essential domain in shaping one's actions. Based on the two definitions of knowledge above, it can be concluded that knowledge is the entirety of human thought obtained from the results of sensing something so that it forms a person's actions and behaviour. Bloom divided human behaviour into three domains: cognitive, affective, and psychomotor. Knowledge is included in the cognitive domain and has six levels: knowing, comprehending, applying, analyzing, synthesizing, and evaluating.

Measurement of knowledge can be done by interview or questionnaire that asks what you want to measure or research from the respondent or research subject. The knowledge measurement results can be adjusted to the levels above to determine the depth of knowledge to be measured. The knowledge depth to be measured and known can be adjusted to the cognitive domain of knowledge. Knowledge category can be determined by the following criteria: (1) good: if the question is answered correctly $76-100 \%$, enough: if the question is answered correctly $56-75 \%$, and (3) less: if the question is answered correctly $<56 \%$.

Knowledge varies from one individual to another. It is influenced by other factors, such as internal factors (e.g. age, gender, education level, and income) and external factors (e.g. mass media). Knowledge can be influenced by several factors, including age, experience, education level, beliefs, facilities and beliefs [21; 22].

\section{RESEARCH METHOD}

This type of research is in the form of quantitative descriptive, which aims to systematically, factually, and accurately regarding the level of knowledge of UKI medical students batch 2016 on X-Ray as a tool to establish a diagnosis. Research data collection was carried out using a crosssectional research design. Namely, measurements or observations were carried out at one time (Notoatmodjo, 2010). This research was conducted through respondents answering structured questions on the questionnaire. Respondents were observed only once. The population in this study were all medical students of the Universitas Kristen Indonesia, batch 2016. Researchers took the respondents of UKI medical students, batch 2016 semester 1, who had just graduated from high school and entered the university level to see respondents' level of knowledge about X-rays. The sample selected in this study were medical students in the first semester of the batch 2016 who had inclusion and exclusion criteria. The minimum sample size used in this study was calculated using the Slovin formula, which was 103 respondents and rounded up to 100 respondents. This research was conducted at the Universitas Kristen Indonesia, to be precise at the Faculty of Medicine. The research process was carried out from September to October, while the data collection was from September 10 to October 30, 2016. The research subjects used by the researchers were medical students at UKI Jakarta. It requires researchers to respect fundamental human rights.

Polit, Beck and Hungler (2001) mention three main ethical references, namely the principle of justice (Justice), the principle of benefit (Beneficienci), and the principle of respecting other people (Respect of human dignity) and collecting data in this study using a measuring instrument in the form of a questionnaire. The questionnaire was developed by the researcher himself based on the research framework, so it is necessary to test the validity and reliability of the instrument. The validity test was carried out by 30 UKI students from the 1 st semester of pediatric medicine faculty. Researchers carried out data processing through editing, coding, processing, and cleaning stages. Then the answers and clarity completeness to the questionnaire questions after all the questionnaires have been collected should be checked. The second stage is coding: researchers convert data in letters into data in the form of numbers to facilitate data 
processing and analysis. The third stage is processing: the researcher enters data into the program on the computer. The last stage is cleaning: the researcher re-checks the data entered to find out the possibility of errors, incompleteness and so on, then corrections are made if there are errors. The researcher used univariate and bivariate analysis to analyze the research results. Univariate analysis was used to analyze the characteristics and level of knowledge of UKI Medical Students. The results of the univariate analysis will be in the form of a frequency distribution that is shown in the table using the number and percentage. Researchers also used bivariate analysis to relate several variables using the Chi-Square test.

\section{RESULT AND DISCUSSION}

Research on the level of knowledge of UKI Medical Students on X-Ray was carried out from September to October 2016, while data collection was carried out from September 10 to October 302016. Data were collected by filling out questionnaires by respondents, namely UKI Medical Students. Researchers distributed 100 questionnaires to respondents at the UKI Faculty of Medicine. Of the 100 questionnaires that the respondents have filled out, all questionnaires are filled.

The study results for the respondents' age were obtained from the mean, median, mode, minimum and maximum values of the respondent's age data. The distribution of respondents based on age can be seen in Table 1 below:

Table 1. Characteristics of Respondents by Age

\begin{tabular}{|l|l|l|l|l|l|}
\hline Variable & Mean & Median & Modus & SD & Min-Max \\
\hline Age & 18,21 & 18,00 & 18 & 1,856 & $16-22$ \\
\hline
\end{tabular}

The mean, median, and mode of age data in this study have different values, so the age data in this study are not normally distributed. Therefore, the median age of UKI Medical Student respondents is 18 years. The results showed that the age range of respondents from UKI Medical Students was 16 to 22 years. Most of the respondents' age is 18 years.
The results showed that most of the respondents were women. The distribution of respondents by gender can be seen in table 2 .

Table 2. Characteristics of Respondents by Gender

\begin{tabular}{|l|l|l|}
\hline Gender & Number & \% \\
\hline Male & 24 & 24,0 \\
\hline Female & 76 & 76,0 \\
\hline Total & 100 & 100,0 \\
\hline
\end{tabular}

The data above shows that most respondents from UKI Medical Students are women $(76.0 \%)$.

Table 3. Distribution of respondents by the school of origin

\begin{tabular}{|l|l|l|}
\hline School Origin & Number & \% \\
\hline Jakarta & 50 & 50,0 \\
\hline Outside Jakarta & 50 & 50,0 \\
\hline Total & 100 & 100,0 \\
\hline
\end{tabular}

The table above shows the number of high school students whose SMA came from Jakarta as many as 50 people $(50 \%)$ and 50 students whose SMA came from outside Jakarta $(50 \%)$. Distribution of respondents based on the most frequently obtained sources of information about XRay.

Table 4. Characteristics of Respondents Based on Information Sources

\begin{tabular}{|l|l|l|}
\hline Information Sources & Number & \% \\
\hline Electronic Media & 60 & 60,0 \\
\hline Writing Media & 14 & 14,0 \\
\hline Subjects in School & 13 & 13,0 \\
\hline Family or Friends & 5 & 5,0 \\
\hline Seminar & 8 & 8,0 \\
\hline Total & 100 & 100,0 \\
\hline
\end{tabular}

The table above shows the most sources of information about X-Ray are electronic media as 60 people $(60.0 \%)$, written media as 14 people $(14.0 \%)$, subjects in school as many as 13 people (13\%), family or friends as many as five people $(5.0 \%)$ and seminars as many as eight people $(8 \%)$.

The following illustrates the level of knowledge of UKI medical students towards X-Ray.

Table 5. Knowledge Level of UKI Medical Students towards X-Ray

\begin{tabular}{|l|l|l|}
\hline Knowledge Leve & Number & \% \\
\hline Good & 53 & 53,0 \\
\hline Enough & 47 & 47,0 \\
\hline Poor & 0 & 0 \\
\hline Total & 100 & 100,0 \\
\hline
\end{tabular}


It can be seen that the number of students who have good knowledge is 53 people $(53.0 \%)$, those who have moderate knowledge are 47 people $(47.0 \%)$, and none have less knowledge of X-Ray.
In this study, bivariate analysis was used to correlate gender, age, and school origin with the level of knowledge.

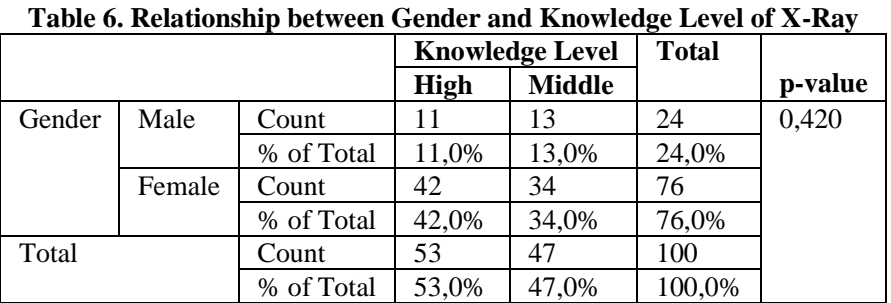

Based on the bivariate analysis, it was found that the male gender with a high level of knowledge was 11 people $(11.0 \%)$, a moderate level of knowledge was 13 people $(13.0 \%)$, and there was no male gender who had a low level of knowledge. The female gender with a high level of knowledge were 42 people $(42.0 \%)$, moderate knowledge level was 34 people (34.0\%), and no female gender had a low level of knowledge. In the Chi-Square test results, the p-value is 0.420 . So there is no significant relationship between gender and the level of student knowledge of X-Ray.

Table 7. Relationship of Age with Knowledge Level of X-Ray

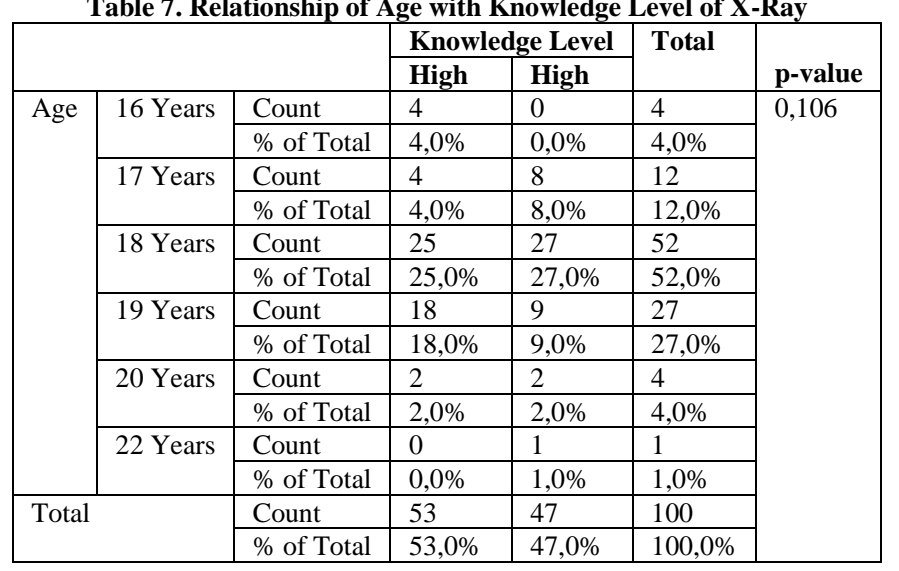

Based on the bivariate analysis, the results obtained were four people aged 16 years with a high level of knowledge (4\%) and no respondents aged 16 years with a moderate or more minor level of knowledge. There are respondents aged 17 years with a high level of knowledge as many as four people (4\%), a moderate level of knowledge as many as eight people (8\%), and no respondent aged 17 years with a low level of knowledge. Respondents aged 18 years with a high level of knowledge as many as 25 people (25\%), a moderate level of knowledge as many as 27 people (27\%), and no respondent aged 18 years with a low level of knowledge. Respondents aged 19 years with a high level of knowledge as many as 18 people (18\%), a moderate level of knowledge as many as nine people (9\%), and none of the respondents aged 19 years with a low level of knowledge. Respondents aged 20 years with a high level of knowledge were two people (2\%), moderate knowledge levels were two people (2\%), and no respondents aged 20 years with a low level of knowledge. There are respondents aged 22 years with a moderate level of knowledge (1\%), and no respondents aged 22 years with a high level of knowledge or less. On the results of the Chi-Square test, the p-value is 0.106 . So there is no significant relationship between 
Richard Yan Marvellini. Medical students' knowledge level about X-Ray as a diagnostic support tool at Universitas Kristen Indonesia, Jakarta batch 2016.

age and the level of student knowledge of X-Ray.

Table 8. Relationship between School Origin and Knowledge Level of X-Ray

\begin{tabular}{|c|c|c|c|c|c|c|}
\hline & \multicolumn{2}{|c|}{ Knowledge Level } & \multirow[t]{2}{*}{ Total } & \multirow[t]{2}{*}{ p-value } \\
\hline & & & High & High & & \\
\hline \multirow{4}{*}{ Schoool Origin } & Jakarta & Count & 35 & 15 & 50 & \multirow[t]{6}{*}{0,000} \\
\hline & & $\%$ of Total & $35,0 \%$ & $15,0 \%$ & $50,0 \%$ & \\
\hline & Outside Jakarta & Count & 18 & 32 & 50 & \\
\hline & & $\%$ of Total & $18,0 \%$ & $32,0 \%$ & $50,0 \%$ & \\
\hline \multirow{2}{*}{\multicolumn{2}{|c|}{ Total }} & Count & 53 & 47 & 100 & \\
\hline & & $\%$ of Total & $53,0 \%$ & $47,0 \%$ & $100,0 \%$ & \\
\hline
\end{tabular}

Based on the bivariate analysis, it was found that 35 students from Jakarta schools had a high level of knowledge of XRay $(35.0 \%)$ and 15 students from Jakarta schools who had moderate knowledge of XRay (15.0\%) ) no students from Jakarta schools who have a low level of knowledge. Students from schools outside Jakarta who have a high level of knowledge of X-Ray are 18 people, moderate levels of knowledge are 32 people (32.0\%), and not students from schools outside Jakarta who have a low level of knowledge of X-Ray. On the results of the Chi-Square test, the pvalue is 0.000 . So there is a significant relationship between school origin and student knowledge of X-Ray.

The results of this study describe the level of knowledge of UKI Medical Students consisting of characteristics, behaviour and level of knowledge. The data from the research are the primary data for a deeper analysis of the level of knowledge of UKI Medical students. Data analysis was carried out by comparing the research data with theories related to knowledge to get a comprehensive and in-depth picture of the level of knowledge of UKI Medical students.

Knowledge is the result of knowing and occurs after someone senses a particular object. Sensing is obtained from all the five human senses, namely sight, hearing, smell, taste, and touch. Most human knowledge is obtained from the five senses of sight and hearing. Knowledge is an essential domain for the formation of one's actions.

Based on the results of univariate analysis, some respondents have high knowledge of X-Ray. Several factors can influence the level of knowledge of UKI
Medical Students. Knowledge can be influenced by several factors, one of which is age. However, based on the Chi-Square test results, there is no relationship between age and level of knowledge. It is not in line with the theory, which says that age affects a person's level of knowledge [23].

However, the results of this study have something to do with the opinion which says that age does not affect a person to seek information and knowledge through the learning process, both formally nonformally [24]. Research conducted on the effect of education, information, age, experience on knowledge shows no relationship between age and knowledge with -value (0.256) [25].

Based on bivariate analysis, it was found that students from Jakarta schools who had a high level of knowledge of XRay were 35 people $(35.0 \%)$ students from Jakarta schools who had moderate knowledge levels were 15 people $(15.0 \%)$ and not students from Jakarta schools that have a low level of knowledge. Students from schools outside Jakarta who have a high level of knowledge of X-Ray as many as 18 people $(18.0 \%)$, a moderate level of knowledge as many as 32 people $(32.0 \%)$, and no students from schools outside Jakarta who have a low level of knowledge of XRay. Moreover, the p-value is 0.000 , which means a significant relationship between school origin and students' level of knowledge. The information is one factor that affects the level of knowledge. Each school in each region must have a different distribution of information. Information obtained from formal and non-formal education can have a short-term effect 
resulting in changes or increases in knowledge [26].

Advances in technology will provide a variety of mass media that can affect student knowledge. As a means of communication, various forms of mass media such as television, radio, newspapers, magazines, and others significantly influence one's knowledge. In delivering information as to its primary task, the mass media also brings suggestions that can direct one's opinion. The existence of new information about a thing provides new cognitive for forming knowledge about it.

This study has limitations, namely: a) This study is a quantitative descriptive study with a cross-sectional design that only wants to describe the characteristics of the level of knowledge of UKI Medical students on X-Ray as a Diagnostic Support Tool, and b) This study took the 2016 UKI medical student respondents who had just completed high school education and had just started the lecture level to facilitate research because the researcher wanted to see the level of knowledge of high school graduate students and compare the level of knowledge of high school outside the region and within the region, therefore to shorten the time In this study, researchers took respondents from UKI Medical students who had just started their lectures.

\section{CONCLUSION}

The following are the conclusions obtained from the results of this study. Namely, most of the respondents have a high level of knowledge of X-Ray, and the source most often used by students to find information about X-Ray is electronic media. Based on the bivariate analysis results, the $p$-value obtained is 0.000 , which means that there is a significant relationship between the respondent's school origin and the level of knowledge of X-rays. Therefore, students are expected to be more active and more active in seeking information about XRay as support for diagnosis from various sources, such as books, magazines, seminars, and social media and further researchers are expected to pay attention to other variables that can affect knowledge and students to X-Ray as support. In addition, the number of respondents would need to be increased to get better and more valid results.

\section{Acknowledgement: None}

\section{Conflict of Interest: None}

Source of Funding: None

Ethical Approval: Approved

\section{REFERENCES}

1. Bercovich, Eyal, and Marcia C. Javitt. "Medical imaging: from roentgen to the digital revolution, and beyond." Rambam Maimonides medical journal 9, no. 4 (2018).

2. Kotwaliwale, Nachiket, Paul R. Weckler, Gerald H. Brusewitz, Glenn A. Kranzler, and Niels O. Maness. "Non-destructive quality determination of pecans using soft X-rays." Postharvest biology and technology 45, no. 3 (2007): 372-380.

3. Russo, Paolo, ed. Handbook of X-ray imaging: physics and technology. CRC press, 2017.

4. Gunderman, Richard B. X-ray vision: the evolution of medical imaging and its human significance. Oxford University Press, 2012.

5. Andreyev, Jervoise. "Gastrointestinal symptoms after pelvic radiotherapy: a new understanding to improve management of symptomatic patients." The lancet oncology 8, no. 11 (2007): 1007-1017.

6. Vano, Eliseo, Luciano Gonzalez, Jose M. Fernandez, and Ziv J. Haskal. "Eye lens exposure to radiation in interventional suites: caution is warranted." Radiology 248, no. 3 (2008): 945-953.

7. Butcher, Ginger. Tour of the electromagnetic spectrum. National Aeronautics and Space Administration, 2010.

8. Makropoulou, M., G. Kareliotis, E. Spyratou, E. Drakaki, A. A. Serafetinides, and E. Efstathopoulos. "Non-ionizing, 
laser radiation in Theranostics: The need for dosimetry and the role of Medical Physics." Physica Medica 63 (2019): 718.

9. Abdullah, Samerra H. "Loosing or damaging occur in x-ray films and Its effects on patient health." Tikrit Medical Journal 19, no. 2 (2013).

10. Jain, Ayushi, Deepti Mittal, Arpita Jindal, Ranjana Solanki, Suman Khatri, Archana Parikh, and Kamlesh Yadav. "Incidentally detected squamous cell carcinoma of renal pelvis in patients with staghorn calculi: case series with review of the literature." International Scholarly Research Notices 2011 (2011).

11. Mitchell, Erica L., and Patricia Furey. "Prevention of radiation injury from medical imaging." Journal of vascular surgery 53, no. 1 (2011): 22S-27S.

12. Lavine, Matthew. "The early clinical Xray in the United States: patient experiences and public perceptions." Journal of the history of medicine and allied sciences 67, no. 4 (2012): 587-625.

13. Guo, Kun, Aliaksandr Baidak, and Zhixin $\mathrm{Yu}$. "Recent advances in green synthesis and modification of inorganic nanomaterials by ionizing and nonionizing radiation." Journal of Materials Chemistry A 8, no. 44 (2020): 2302923058.

14. Stewart, F. A., A. V. Akleyev, M. HauerJensen, J. H. Hendry, N. J. Kleiman, T. J. Macvittie, B. M. Aleman et al. "ICRP publication 118: ICRP statement on tissue reactions and early and late effects of radiation in normal tissues and organsthreshold doses for tissue reactions in a radiation protection context." Annals of the ICRP 41, no. 1-2 (2012): 1-322.

15. Einstein, Andrew J., Kevin W. Moser, Randall C. Thompson, Manuel D. Cerqueira, and Milena J. Henzlova. "Radiation dose to patients from cardiac diagnostic imaging." Circulation 116, no. 11 (2007): 1290-1305.

16. Sherer, Mary Alice Statkiewicz, Paula J. Visconti, E. Russell Ritenour, and M. S. R. S. Kelli Haynes. Radiation protection in medical radiography. Elsevier Health Sciences, 2013.

17. Hansson, Sven Ove. "Ethics and radiation protection." Journal of Radiological Protection 27, no. 2 (2007): 147.

18. Sholihah, Q., W. Kuncoro, R. A. Sari, R. P. Lukodono, and S. E. Swara. "Risk management of the implementation of work health safety in radiology." Utopía y praxis latinoamericana: revista internacional de filosofía iberoamericana y teoría social 6 (2019): 142-152.

19. Mohapatra, Abhisekh, Roy K. Greenberg, Tara M. Mastracci, Matthew J. Eagleton, and Brett Thornsberry. "Radiation exposure to operating room personnel and patients during endovascular procedures." Journal of vascular surgery 58, no. 3 (2013): 702-709.

20. Ammad, Syed, Wesam Salah Alaloul, Syed Saad, and Abdul Hannan Qureshi. "Personal protective equipment (PPE) usage in construction projects: A scientometric approach." Journal of Building Engineering 35 (2021): 102086.

21. Ifinedo, Eloho, Jenni Rikala, and Timo Hämäläinen. "Factors affecting Nigerian teacher educators' technology integration: Considering characteristics, knowledge constructs, ICT practices and beliefs." Computers \& education 146 (2020): 103760.

22. Tan, Boon-Kiang, Anne J. Smith, Peter B. O'Sullivan, Gang Chen, Angus F. Burnett, and Andrew M. Briggs. "Low back pain beliefs are associated to age, location of work, education and pain-related disability in Chinese healthcare professionals working in China: a cross sectional survey." BMC Musculoskeletal Disorders 15, no. 1 (2014): 1-13.

23. Khandekar, Rajiv, Saleh Al Harby, Harith Al Harthy, and Jawad Al Lawatti. "Knowledge, attitude and practice regarding eye complications and care among Omani persons with diabetes-A cross sectional study." Oman journal of ophthalmology 3, no. 2 (2010): 60.

24. Stern, Michael J., Shelia R. Cotten, and Patricia Drentea. "The separate spheres of online health: Gender, parenting, and online health information searching in the 
Richard Yan Marvellini. Medical students' knowledge level about X-Ray as a diagnostic support tool at Universitas Kristen Indonesia, Jakarta batch 2016.

information age." Journal of family issues 33, no. 10 (2012): 1324-1350.

25. Hirfanoglu, Tugba, Ayse Serdaroglu, Ali Cansu, A. Sebnem Soysal, Eda Derle, and Kivilcim Gucuyener. "Do knowledge of, perception of, and attitudes toward epilepsy affect the quality of life of Turkish children with epilepsy and their parents?." Epilepsy \& Behavior 14, no. 1 (2009): 71-77.

26. Simac, Julia, Rachel Marcus, and Caroline Harper. "Does non-formal education have lasting effects?." Compare: A Journal of Comparative and International Education 51, no. 5 (2021): 706-724.

How to cite this article: Richard Yan Marvellini. Medical students' knowledge level about X-Ray as a diagnostic support tool at Universitas Kristen Indonesia, Jakarta batch 2016. Int J Health Sci Res. 2022; 12(2):318328. DOI: https://doi.org/10.52403/ijhsr. 20220242 